\title{
Importance of Health Promotion and Education to Young People in Educational Institutions (Schools)
}

\author{
Genta Nallbani \\ PhD, Sport University of Tirana, Faculty of \\ Movenment Science, Department Medicine of Sport
}

\section{Abstract}

It is important that in educational institutions to develop trainings and classes with a focus on health education and the acquisition of necessary knowledge.This study aims to give a specific approach regarding the importance of health education promotion in educational institutions with a focus on educational and health-educational activities in particular based on health and which aims to increase the level of health education to learn and implement healthy behaviours.In this study were included 130 students in elementary and secondary schools aged $14-18$,of whom $(n=81)$ females and $(n=49)$ males.The questionnaire was based on the knowledge of these students about health promotion and education as well as organizational activities related to health education by progressing in terms of the level of knowledge, attitudes and behaviours related to health.In the results of this survey was observed that a small number of them $21 \%$ had information on the promotion and development of various activities related to health. With a total of $56 \%$ women and $44 \%$ men responding that some form of activities or programs to promote public health such as posters or tasks related to certain topics have started to be developed by teachers.The lack of these activities and promotional programs requires that in the future to increase support in this direction enabling to plan in detail the development of educational and health promotional activities where the information is scientifically based and the way of communication and information is as clear and accurate as possible to have more acceptability,liking and the highest reliability.

Key words: Health education, promotion, young people, educational institutions

\section{Introduction}

Health promotion covers all aspects of activities and programs that aim to improve the health of individuals and the community (1).It includes any combination of educational and ecological support for actions and living conditions that improve and promote the health of everyone $(2,3)$. Health promotion is the process of training individuals to increase and improve their control over their health (Ottawa Charter) 
(4). We can say with conviction that health promotion focuses on achieving equality in health for all individuals in the community. The promotion of health in schools represents a small and ideal world in which the beliefs, thoughts, knowledge, attitudes and habits will largely determine the evolution of the individual towards maturity, and will play a special role and contribution to its social life (5).In this respect, the cooperation between the world of health care and that of education and training represents a fundamental element for the development of activities that allow the management of processes which are overloaded by numerous pressures, especially commercial ones aimed at favouring the consumption of tobacco, alcohol, sugary drinks, high-calorie foods and drinks, through often contradictory media messages. Scientific evidence shows that a limited number of behaviours contribute to a large extent to determine some of the leading causes of death affecting our society, such as cancer and accidents.These behaviours, often developed at a young age, include the consumption of tobacco, psychotropic substances, alcohol, unhealthy diets, physical activity, and inappropriate sexual behaviours (6). Promoting health in schools is one of the basic elements of student education for which schools should invest today and in the future. Promoting health in school settings is important because health and education are closely linked.Healthy children are more likely to be more effective. Education plays an important role in the economic development and lifelong health outcomes.Promotion of health in all preschool and school cycles through the development of educational activities in general and educational-health in particular, both inside and outside the compulsory educational programs, in order to be continuous and systematic (7).The importance of health promotion in schools is great, as the school is the institution which covers a large part of the population, including young people. To achieve these objectives and common learning skills for all health education programs we must aim to analyse health content and improve the old methodologies that have characterized interventions so far. Quotes in school are often episodic, non-participatory and informative only. The core values of a health promotion school initiative which is also done through partnership can be to promote health through the topics, contents and methods analysed in order to highlight and overcome the fragmentation and operational disommogeneity that so far has not allowed a realistic assessment and reproducibility of the interventions performed (9). Nutrition, physical activity, sexuality, alcohol, psychotropic substances, smoking, other addictions, road accidents, mobility in home and stable conditions constitute the content of the following educational-health information which provides, for each field, the definition of the problem, identification of risk factors and protection factors. Presentation of national and international articles and guidelines, references to projects already completed on topics which include different geographical realities, learning objectives as well as teaching methods and tools for teaching in the field of health promotion and education serve as a key point for everyone's health as health is a value and fundamental right which we must preserve and take care of at all times.Given that health promotion is not only about changing behaviour but also about intervening in political, social and organizational factors, it is worth mentioning 
the presence of numerous studies that highlight how health education conducted in schools is effective in reducing the prevalence of behaviours dangerous to the health of young people. In our context, health promotion can be presented as a combination of health education, and other activities that schools can undertake to maintain and improve the health of all those who are part of these institutions (8). We all care for chilldren, every child and young person has the right, and should have the opportunity, to be educated in school to promote health. The school represents, in fact, an essential meeting place for any serious and real health program which wishes to achieve a broad and positive impact on the health of the whole country as, more than any other institution, it can help you live in a healthier, more satisfying and productive way by helping to acquire knowledge and skills necessary to avoid risky behaviours.(10).School can also allow for the development of autonomy and empowerment processes by aiding learning skills such as knowing how to make decisions, communicate effectively, and resist external influences by making healthy behavioural choices.

\section{Methodology}

For the collection of this data was taken a volunteer sample to be part of this study from elementary and secondary school in Tirana.Of 150 questionnaires distributed 130 was valid so the final sample consisted of 130 subjects.Quantitative research was used where an anonymous questionnaire was completed based on the research method (observation) respectively through the survey method and the interview method.The questionnaire consists of 18 closed questions which in the first part deals with information about the use of alcohol and tobacco, in the second part the knowledge which is related to sexually transmitted infections, as important issues related to the health of young people and in the third part they were also asked about the development of promotional and informational activities in school, in relation to these important issues directly related to health.In completing this questionnaire participated 130 students aged 14-18 years, of whom $(n=81)$ females and $(n=49)$ males.

\section{Results}

Respectively in this study we found that $73.3 \%$ females and $26.66 \%$ males have shown that they have general knowledge about sexually transmitted infections but not in detail, this information that remains evasive and unclear, where it is worth noting that today this information about sex and sexually transmitted infections has never been so extensive and diverse. Therefore, it is very important that through activities or services for health promotion we must properly orient young people towards accurate and appropriate information. Also $65.5 \%$ of females and $34.5 \%$ of males showed a low level of support for the organization of various health promotional activities whether from school, other organizations or local institutions.In terms of consumption of tabaco and alcohol as well as the damage and dependence that these substances cause for human body especially in young people 
the answers have been that $75.2 \%$ males and $24.8 \%$ females admitted that the consumption of these substances was started simply as something different without actually realizing the real danger caused by their abuse. There has been a more positive approach, with a total of $56 \%$ females and $44 \%$ males responding to some form of activities or programs to promote public health such as posters or assignments related to certain topics by teachers, among which stated that recently, a number of activities have been developed as well as promotional programs for the necessary elaboration of human behaviors with a focus on educational health of various forms and dimensions. Most of the questions identified in relation to other health promotion activities have been answered of which show a low percentage $21 \%$ of development of these activities in general.

\section{Discussion}

As can be from the data reported in this study, knowledge and information exist in general but not in a detailed and specific way, and in this aspect the information must have a high level of acceptability, liking and reliability.The aim is not only to standardize accurate information about the health of young people, but also to raise awareness and enable them for a healthy life as they move through the stage of physiological and mental growth where there are not only the young people themselves who can pass the information on to each other but also the teachers.Therefore, in the future there should be increased activities and support in this regard. Promotional activities in schools are essential for students in raising awareness and caring for a healthier life. It is therefore expected that in the future there will be an increase in health promotional activities in schools, as health promotion interventions carried out so far in schools are often characterized by fragmentation and operational disommogeneity and their evaluation and reproducibility has not always been possible.The promotional programs themselves, the topics and contents of the respective interventions according to the age groups should gradually increase, advancing towards the level of knowledge, attitudes, habits and behaviours related to health.

\section{Conclusion}

These types of studies need to be extended more widely to the population with a large representation of children, pupils, students and parents, not only in urban areas but also in rural areas where it is known that many of these topics are still taboo, where these health promotion activities as well as the relevant topics should be conceived in function of the needs, problems and concrete priority situations. It is important for young people to learn from reliable and impartial sources of information, discuss with health care professionals, choose which option is right for them, so that the risk to their lives is minimal. Through which to be tested and to evaluate the perceptions and life practices related to health, evaluating the situations in a way to be served with the necessary interventions, appropriate and concrete improvements, for living everywhere more and more healthy and where the information is scientifically based 
and the way of communication and information is as clear and accurate as possible to have more acceptability, liking and the highest reliability.

\section{Recommendations}

Therefore, these data can show that it is very important that through activities or services for health promotion we must properly orient young people towards accurate and relevant information. The school also welcomes all age groups during development for a long period of their lives and should provide them with the opportunity to observe and monitor the growth path and the model of health and well-being in which the individual is focused by strengthening the concept of their personal and being healthy.

\section{References}

[1] Dennis J, Draper P, Holland S, Shipster P, Speller V and Sunter J (1982) Health Promotion in the Reorganised NHS. Unit for Study of Health Policy, London.

[2] Green,L.W,Kreuter,M.W.,Partrige,K.,and Deeds,S.Health Education Planning:A Diagnostic Approach.Montain View,Calif::Mayfield,1980.

[3] Green,L.W.,Krewter,M.W.Health promotion planning: An Educational and Environmental Approach (2nd ed.).Mountain V,Calif.:Mayfield, 1991.

[4] "OTTAWA CHARTER FOR HEALTH PROMOTION" ,Health Promotion, 1st International Conference on Health Promotion, Ottawa, Ontario, CANADA, 21 November 1986.

[5] World Health Organization.The europian network of health promoting schools.WHO, Copenhagen, 1993.

[6] LAY I.: "Per una Pedagogia della Salute" in 'La Salute Umana' NO 139,CSESi,Perugia.

[7] Radat K,Speed M Sex education,sexual behaviour and attitudes of young people.In: Glanz A,Mc Vey D,Glass R (eds) Talking about it: Young people, sexual behaviour. HEA,London,1994.

[8] "HEALTH EDUCATION IN MEDICAL EDUCATION - The need for a strategy"[Ed.By Briziarelli L.\& coll.] (1993),Internatinal Union for Health Education (Europian Bureau) \& CEES (Perugia), Spons . Fondazione A .Celli per una cultura di salute,Perugia.

[9] Hopson B,Scally M.Life skills teaching programmes 1,2,3,4.Life skills Associates,Leeds 1980,1982,1985,1987.

[10] Jack MS. Personal Fable: A potential explanation for behavior in adolescents. Journal of Pediatric Nursing. 1989; (4): 334-8. 